
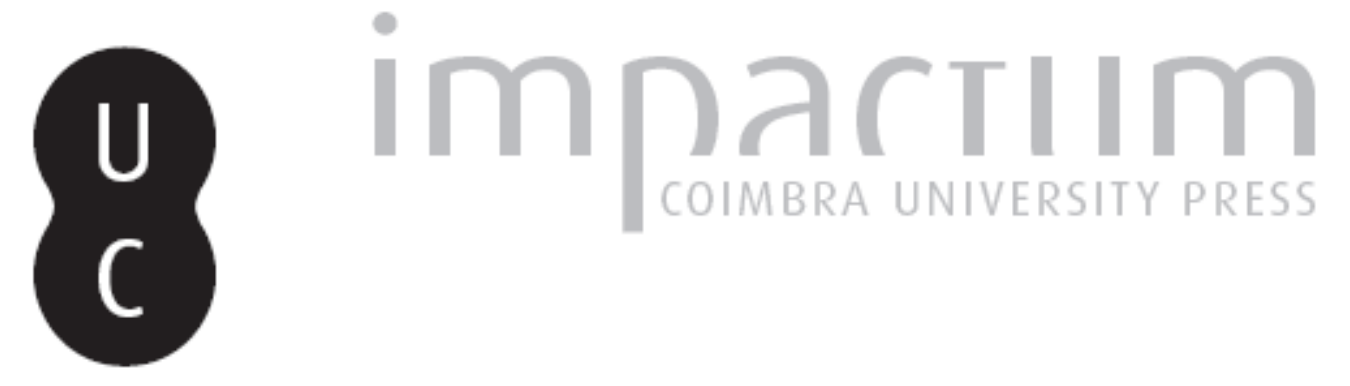

\title{
[Recensão a] James K. Farge, Biographical Register of Paris Doctors of Theology 1500-1536
}

Autor(es): $\quad$ Rodrigues, Manuel Augusto

Publicado por: Imprensa da Universidade de Coimbra

URL persistente:

URI:http://hdl.handle.net/10316.2/45292

DOI:

DOI:https://doi.org/10.14195/2183-8925_8-1_32

Accessed : $\quad$ 26-Apr-2023 13:05:06

A navegação consulta e descarregamento dos títulos inseridos nas Bibliotecas Digitais UC Digitalis, UC Pombalina e UC Impactum, pressupõem a aceitação plena e sem reservas dos Termos e Condições de Uso destas Bibliotecas Digitais, disponíveis em https://digitalis.uc.pt/pt-pt/termos.

Conforme exposto nos referidos Termos e Condições de Uso, o descarregamento de títulos de acesso restrito requer uma licença válida de autorização devendo o utilizador aceder ao(s) documento(s) a partir de um endereço de IP da instituição detentora da supramencionada licença.

Ao utilizador é apenas permitido o descarregamento para uso pessoal, pelo que o emprego do(s) título(s) descarregado(s) para outro fim, designadamente comercial, carece de autorização do respetivo autor ou editor da obra.

Na medida em que todas as obras da UC Digitalis se encontram protegidas pelo Código do Direito de Autor e Direitos Conexos e demais legislação aplicável, toda a cópia, parcial ou total, deste documento, nos casos em que é legalmente admitida, deverá conter ou fazer-se acompanhar por este aviso.

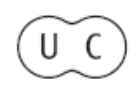


REVISTA DE HISTÓRIA DAS IDEIAS $\mathbf{8}$

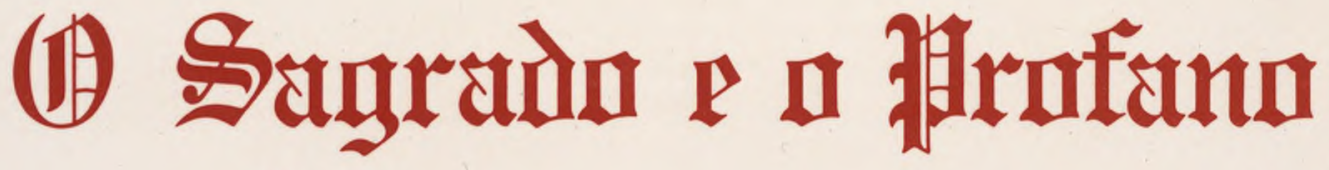 s.1. \\ HOMENAGEM A J. S. DA SILVA DIAS}

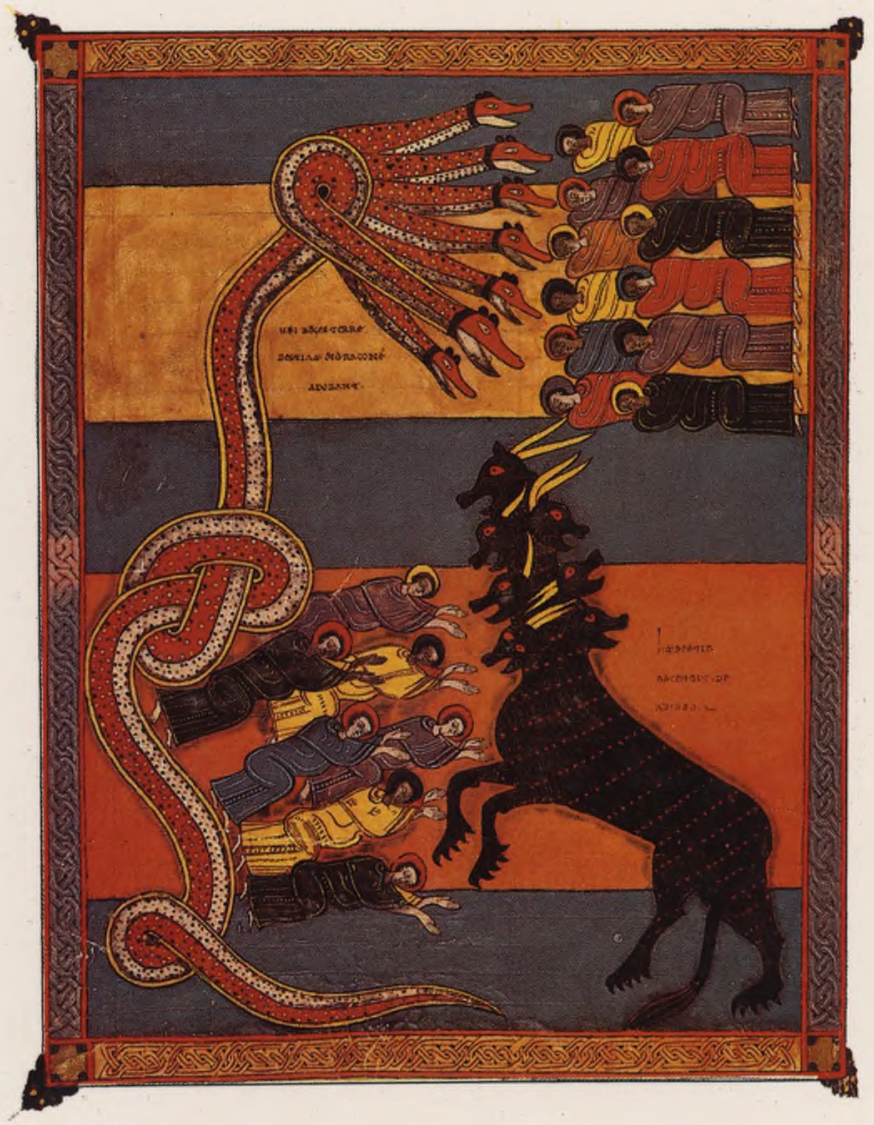

INSTITUTO DE HISTORIA E TEORIA DAS IDEIAS FACULDADE DE LETRAS 
James K. Farge, Biographical Register of Paris Doctors of Theology 1500-1536. Pontifical Institute of Medieval Studies, col. «Subsidia Medievalia», n. ${ }^{\circ}$ 10. Toronto, 1980. XVI+526 p.

A colecção «Subsidia Medievalia» a cargo do Pontifício Instituto de Estudos Medievais de Toronto passa agora a ficar mais valorizada com o presente livro da autoria de um notável especialista de temas relacionados com a Universidade de Paris, o Prof. James K. Farge. No prefácio Jean Claude Margolin explica como surgiu a obra e testemunha o melhor elogio pelo trabalho realizado que merece ao Autor uma introdução excelente na qual fornece os elementos julgados mais importantes sobre o mesmo.

Ao todo são incluídos 474 nomes de doutores teólogos pela Universidade de Paris, desde 1500 a 1536. Dados sobre a família, a preparação científica pré-universitária, a carreira estudantil, a actividade na Faculdade de Artes e outras, benefícios, data da morte e bibliografia, são fornecidos acerca de cada um deles. Trata-se de um instrumento de trabalho precioso', fruto de pesquisas bastante minuciosas e caracterizadas por um grande rigor científico. Figuras célebres, como Noël Beda, Juan de Celaya, Jérôme Clichtove, Pierre Cousturier, Pierre Dore, Jean de Gaigny (Gagnaeus), Nicolas Le Clerc, François Le Picart, John Mair, Pedro Ortiz, Guillaume Petit, Francisco* de Vitoria e muitos outros figuram nesta obra. Entre os portugueses, contam-se João Claro, Álvaro Gomes, Diogo de Gouveia e Pedro de Meneses.

A parte final do* livro contém um capítulo sobre as fontes (impressas e manuscritas) que se reveste de extraordinário merecimento. O mesmo se diga da bibliografia e dos índices finais. Estamos perante um autêntico monumento de saber e erudição que devia servir de modelo para o estudo da história de todas as Universidades.

\section{Manuel Augusto Rodrigues}

Antonio García y García, Iglesia, Sociedad y Derecho. Bibliotheca Salmanticensis. Estudos n. ${ }^{\circ}$ 74. Universidad Pontificia de Salamanca e Biblioteca de la Caja de Ahorros y M. de P. de Salamanca. Salamanca, 1985, 485 p.

O Prof. Antonio García y García tem-se dedicado ao longo de mais de um quarto* de século à investigação e à docência e publicou nesse espaço de tempo numerosos livros e artigos que 